\title{
SARTI, Cynthia; DUARTE, Luiz Fernando Dias (Orgs.). Antropologia e ética: desafios para a regulamentação. Brasília: ABA, 2013. 239 p.
}

\author{
Marcia Aparecida Alferes* \\ Silvana Stremel ${ }^{* *}$
}

A coletânea "Antropologia e ética: desafios para a regulamentação", organizada por Cynthia Sarti (UNIFESP) e Luiz Fernando Duarte (UFRJ) é fruto de discussões realizadas no âmbito da Associação Brasileira de Antropologia (ABA) sobre a produção do conhecimento antropológico e a regulação da ética em pesquisa no Brasil através da Resolução no 196/96 do Conselho Nacional de Saúde, vinculado ao Ministério da Saúde. A ABA, preocupada com as questões referentes à ética no contexto de expansão e transformação da Antropologia no Brasil, tem promovido reflexões propositivas e ações políticas sobre a forma de avaliar a ética em pesquisa na área e, por conseguinte, nas Ciências Humanas. Essa publicação delineia as principais questões, dilemas e desafios da regulamentação brasileira da ética em pesquisa ante a especificidade desse campo do conhecimento.

A Resolução no 196/96 e suas complementares, aprovadas pelo Conselho Nacional de Saúde, foram implementadas pela Comissão Nacional de Ética em Pesquisa (CONEP) e pelos Comitês de Ética em Pesquisa (CEPs), sendo obrigatórias para todas as áreas de conhecimento em todas as instituições de Ensino Superior e de pesquisa. A crítica frente a essa regulamentação se dá pelo fato de que tais resoluções foram fortemente influenciadas pelo campo biomédico. $\mathrm{Na}$ sua formulação, tomaram como referência documentos internacionais sobre o tema, elaborados por associações médicas (Código de Nuremberg, Declaração de Helsinki, diretrizes propostas pelo Council for Internacional Organizations of Medical Sciences). Dessa forma, os dilemas éticos envolvidos nas pesquisas da área das Ciências Humanas e Sociais e a sua especificidade não foram nelas contemplados. A partir desse impasse, que as discussões do livro são encaminhadas, suscitando a imprescindibilidade da regulamentação da ética em pesquisa de maneira que sejam consideradas as singularidades das áreas de conhecimento.

\footnotetext{
* Doutoranda no Programa de Pós-Graduação em Educação da Universidade Estadual de Ponta Grossa. E-mail: < profsecr@hotmail.com>

** Doutoranda no Programa de Pós-Graduação em Educação da Universidade Estadual de Ponta Grossa. E-mail: <silvanastremel@gmail.com>
} 
Organizada em cinco capítulos e dois anexos referentes à Moção da ABA de 2011 e ao Código de Ética da ABA, a obra apresenta experiências concretas de pesquisas antropológicas que ressaltam como as questões éticas emergem nas situações empíricas e implicam em negociações constantes entre os sujeitos envolvidos, pesquisador e pesquisados. Essa relação entre os envolvidos é marcada pela tensão entre proximidade e distanciamento e supõe múltiplas possibilidades de interlocução dos termos éticos que se definem como "algo em movimento". (SARTI; DUARTE, 2013, p. 27). Em virtude disso, um dos aspectos problemáticos apontados na obra referente à regulamentação da ética em pesquisa no Brasil, é a inadequação do Termo de Consentimento Livre e Esclarecido (TCLE), o qual deve ser formulado de maneira prévia à pesquisa. No caso da pesquisa em Antropologia, os textos mostram, como uma especificidade da área, que durante o trabalho de campo, muitas são as situações imprevistas que não podem ser definidas antecipadamente.

O texto de Patrice Schuch (UFRGS) intitulado "A vida social ativa da ética na Antropologia (e algumas notas do 'campo' para o debate)" à luz do conceito analítico "vida social ativa" de Lila Abu-Lughod, argumenta como fundamental considerar os múltiplos domínios em que a ética existe na Antropologia, visto que a ética é diferencialmente produzida na diversidade dos espaços da prática antropológica. A partir dessa ideia, a autora analisa sobre alguns domínios em que a relação entre ética e Antropologia ganha vida social ativa, a partir da bibliografia brasileira, considerando especialmente dois livros: "Antropologia e ética: o debate atual no Brasil" (2004) e "Ética e regulamentação na pesquisa antropológica" (2010).

Patrice Schuch classifica três domínios em que a ética emerge como espaço de problematizações: 1) O pesquisar/atuar: autorreflexão, responsabilidade e prática política; 2) Antropologia e multidisciplinaridade: ciência e sua inserção social; 3) A ética como campo de regulamentações: quando dizer não, não basta. O primeiro domínio caracteriza-se pela complexidade do pesquisar/atuar que envolve os modos de relacionamento do antropólogo com os sujeitos de pesquisa e a reflexão daquilo que constitui a tarefa antropológica e suas responsabilidades. A autora destaca nesse ponto que o trabalho do antropólogo pode gerar muitos desdobramentos políticos e sociais para os contextos pesquisados, assim, a questão da "produção do conhecimento com responsabilidade [...] parece ser o próprio sentido da ética nesse espaço ativo de sua vida social" (SCHUCH, 2013, p. 44). O segundo refere-se à discussão de relacionar a ética aos princípios e procedimentos de pesquisa em colaboração com outros conhecimentos. Por último, o terceiro domínio a autora aborda sobre as regulamentações da ética e os seus órgãos de controle, além de analisar aspectos do Código de Ética da ABA. Com base no exemplo da sua própria pesquisa, Patrice Schuch finaliza o 
capítulo problematizando sobre o que acontece quando alguns desses domínios parecem estar em contradição.

O segundo capítulo "Desafios à Antropologia: diálogos interculturais entre os 'outros' de ontem, os protagonistas de hoje e os antropólogos 'situados"' de autoria de Jane Felipe Beltrão (UFPA), aborda a discussão da ética como algo a ser elaborado e pensado pelo antropólogo em conjunto com os sujeitos, no seu caso os indígenas. Nesse sentido, a autora salienta que os antropólogos têm sido treinados para compreender a diversidade, mas ainda de forma a explicar o “outro" e não a trabalhar junto com o "outro". A pesquisadora coloca em pauta a questão da interculturalidade na produção escrita e expõe a sua vivência em escrever com pessoas indígenas. O que evidencia "é a discussão de autorias como escrita reflexiva e crítica para dar conta de situações etnográficas novas (nas quais os interlocutores são também intérpretes).” (BELTRÃO, 2013, p. 93).

No artigo de Ceres Víctora (UFRGS), cujo título é "O ético e o legal nos processos de apropriação profissional da experiência social”, a autora analisa como um grupo indígena (os Charruas) reage a um documentário sobre sua vida, de modo que alegam não se reconhecerem no trabalho final que lhes foi apresentado e por isto movem uma ação junto ao Ministério Público contra os produtores e a diretora do filme. Nesta ação vários argumentos foram utilizados, dos quais nove se destacam e são relatados pela autora do artigo. O primeiro argumento é que a versão final do filme não corresponde ao acordo realizado entre o grupo indígena e as realizadoras, pois acreditavam que o filme trataria exclusivamente sobre eles. Isso não ocorreu segundo o grupo visto que foram utilizadas no filme imagens e depoimentos de outras etnias. Quanto ao material de promoção e divulgação do filme o grupo alega que as realizadoras misturaram símbolos de diferentes etnias. Além disso, segundo o grupo não foram utilizadas todas as cenas filmadas e que eles consideravam fundamentais. No filme foram mostradas obras de arte de autoria da comunidade Charruas sem a concessão devida dos créditos. Entre outros argumentos o grupo declarou que o contrato foi assinado, mas que a Cacique que o assinou não sabia ler, e que apenas sabia escrever o nome. Os argumentos foram aceitos pela Defensoria Pública, que em outubro de 2009 iniciou uma ação pedindo a suspensão da exibição do documentário. O pedido foi indeferido por decisão de um juiz federal que alegou não ter havido descumprimento contratual.

O objetivo do artigo foi a partir do caso descrito, refletir sobre os processos de transformação profissional da experiência social resultantes de pesquisas, filmagens, fotos, de maneira a mostrar os limites éticos e questionar a transformação inesperada provocada pela intervenção de profissionais sobre o grupo indígena. 
Ceres Víctora (2013, p. 107) expõe que se pode dizer que essa transformação é em certo sentido inevitável, pois “[...] toda a descrição com palavras e imagens da experiência de pessoas e grupos na forma de uma tese, de um livro, ou de um filme, configura uma forma de apropriação da experiência do outro". Diante dessa situação, a autora aborda que a questão que se coloca é como retratar e/ou interpretar a realidade do outro de forma ética e responsável. Para tal é relevante destacar os questionamentos que a autora faz sobre qual seria o limite entre o (i)legal e o eticamente im(próprio) e quais os mecanismos que os grupos atingidos possuiriam para defender seus interesses diante de uma ou outra situação. E ainda, o que está ao alcance dos grupos que foram estudados, fotografados, filmados, quando eles percebem que a sua experiência social e histórica foi transformada em formas inesperadas e inapropriadas.

No seu entendimento sobre o caso, a autora revela que as dimensões morais e éticas que estão para além das legais, deveriam ser consideradas, tendo em vista as características do grupo indígena. "Já que diferentes profissionais nem sempre têm formação para atentar para essas dimensões, penso que a justiça tem um papel a cumprir na definição do meio termo entre a liberdade de expressão dos profissionais e o direito dos grupos de serem reconhecidos e respeitados nas suas peculiaridades" (VÍCTORA, 2013, p. 129).

O artigo "Etnografia entre 'éticas': ética e pesquisa com populações indígenas", de Marina Cardoso (UFSCar), tem como objetivo abordar, a partir de um relato de experiência etnográfica, que há outras dimensões da ética em pesquisa que não são passíveis de serem regulamentadas a partir de procedimentos formais para sua consecução. Essa abordagem faz parte do rol de discussões sobre a Resolução no 196/96 do Conselho Nacional de Saúde, que lançou as diretrizes e normas para regulamentar as pesquisas envolvendo seres humanos.

A história relatada pela autora mostra a relação da mesma com um grupo de indígenas e o interesse deles em possuir parcerias com instituições, com o intuito de terem suas demandas atendidas por essas instituições, através de seus profissionais. A relação de "troca" descrita pela autora é um fato interessante, pois esta troca de informações entre antropólogos e sujeitos provém das relações construídas no campo de pesquisa e podem se estender fora dele. São relações que se diferem das comerciais, pois podem ser relações de amizade, de reciprocidade e até mesmo de parentalidade.

Dada essas relações, considera-se a necessidade de praticar boas condutas na pesquisa científica, pois conforme afirma Cardoso (2013, p. 156) “[...] essas relações perduram fora do tempo e do campo de pesquisa estrito senso, e fazem parte de uma ética definida não pelos antropólogos, mas pelos próprios povos com quem se disponham a trabalhar, ou que se disponham também a trabalhar com eles”. 
A ética definida pelos próprios povos pesquisados refere-se também à permissão para realização da pesquisa em suas comunidades, que depende da concordância da própria comunidade local, além das lideranças local e institucional. Isto se deve ao fato de que nenhuma pesquisa é neutra, o que leva a reflexão sobre qual é o engajamento do pesquisador, seja ele antropólogo ou não, e qual será o retorno que o pesquisador pode oferecer para determinado contexto.

O fato de que todas as pesquisas, incluindo as pesquisas etnográficas, tenham que se submeter a uma jurisdição da área biomédica com protocolos diferenciados, tais como o Termo de Consentimento Livre e Esclarecido (TCLE) deixa Marina Cardoso um tanto intrigada, devido às características desse tipo de pesquisa. Para a autora, a pesquisa etnográfica possui dimensões éticas específicas, que dependem quase que exclusivamente da inserção do pesquisador na comunidade e das relações que ele estabelece com os sujeitos da pesquisa, os quais, muitas vezes, estabelecem o seu próprio conceito sobre ética. Dessa forma, a autora enfatiza que não deveria ser da competência da CONEP ${ }^{1}$ avaliar projetos de pesquisa etnográfica. No que se refere às populações indígenas, a autora argumenta a necessidade de se considerar as suas especificidades e lhes garantir os direitos de participar da tomada de decisões sobre as pesquisas que serão realizadas em suas comunidades.

Mariana Tello (UNC - Argentina) em seu texto "Ética y antropología de la violencia", busca analisar a relação entre a ética e a Antropologia por meio de experiências de investigação sobre violência, conflitos sociopolíticos e direitos humanos na Argentina.

Assim, como Ceres Víctora e Marina Cardoso, Mariana Tello realiza sua análise a partir de uma experiência etnográfica, não com indígenas, mas com sobreviventes do campo de extermínio de "La Perla" na Argentina. O primeiro aspecto básico que a autora destaca para a realização da pesquisa refere-se às questões éticas e metodológicas. De acordo com seu texto, percebe-se a relevância em obter o consentimento daqueles que irão participar da pesquisa, informa-los sobre como as informações partilhadas serão utilizadas e devolver as entrevistas a eles para correções.

O consentimento informado seria na perspectiva da autora um procedimento que respeita o direito das pessoas de serem informadas sobre os objetivos da pesquisa e concordarem ou não em participar. Além disso, o consentimento

\footnotetext{
${ }^{1}$ A Resolução no 466 de 12 de dezembro de 2012, determina que a Comissão Nacional de Ética em Pesquisa (CONEP) é uma instância colegiada, de natureza consultiva, deliberativa, normativa, educativa e independente, vinculada ao Conselho Nacional de Saúde/Ministério da Saúde. Entre suas atribuições está a de examinar os aspectos éticos de pesquisas envolvendo seres humanos, analisando e monitorando os protocolos de pesquisa que envolvam necessidade de maior proteção em relação aos seus participantes, em especial os riscos envolvidos.
} 
informado que procura ter um alcance universal, adquire um significado específico de acordo com o grupo com o qual se está trabalhando. Como parte fundamental da negociação ética entre pesquisador e pesquisados, o consentimento informado contribuiu para a pesquisa da autora, pois ao tratar de um tema tão delicado, o qual envolvia os sentimentos das pessoas, inclusive os seus próprios, por ter ela vivenciado uma experiência de violência, seria difícil manter o equilíbrio entre o compromisso ético e o distanciamento necessário à análise do tema.

No campo da pesquisa etnográfica, as relações com as pessoas envolvidas na pesquisa e a ética nessa relação, foram cruciais para a autora compreender as informações coletadas e revelar o seguinte:

Esto me llevó a pensar en la tensión implícita entre recordar y olvidar experiencias sumamente traumáticas, donde el simple hecho de preguntar implica despertar recuerdos dolorosos y el publicar esa información, como hemos visto anteriormente, modifica las representaciones de sí y ante otros de las personas con las que trabajamos. A partir de esto, comencé a plantear las citas con los sobrevivientes con unos días de anticipación, de modo de que pudieran "prepararse" para "entrar" en el relato de la experiencia. (TELLO, 2013, p. 209).

Os artigos contidos nesta coletânea fazem parte de uma retomada das discussões sobre a Resolução no 196/96, do Conselho Nacional de Saúde, vinculado ao Ministério da Saúde, que lançou as diretrizes e normas para regulamentar as pesquisas envolvendo os seres humanos. É interessante destacar que, tendo em vista a necessidade de revisões, a Resolução no 196/96 foi revogada pela Resolução no 466, de 12 de dezembro de 2012.

Um aprofundamento nos estudos de ambas as Resoluções faz-se necessário por todos aqueles que pretendem fazer pesquisa com seres humanos, seja no campo da Antropologia ou áreas afins. As reflexões apresentadas nos artigos contribuem para esses estudos, pois os autores argumentam que a elaboração da Resolução no 196/96 foi baseada nas necessidades das pesquisas biomédicas e equivocadamente estendida a todas as pesquisas, de todas as áreas do conhecimento.

Desde então as pesquisas, sejam ou não na área da saúde, devem submeter-se à avaliação dos Comitês de Ética em Pesquisa (CEPs) e em alguns casos, à Comissão Nacional de Ética em Pesquisa (CONEP). Tal fato tem gerado discussões no âmbito dos cursos de graduação e pós-graduação das universidades, que tem resultado na criação de fóruns de discussão e grupos de trabalho, com o objetivo de garantir meios para que as peculiaridades das áreas que não são da saúde sejam consideradas, quando os seus projetos de pesquisa são avaliados. A Antropologia é a área que mais avançou nessas discussões, bem como nas 
questões éticas. Isso é o que se percebe nos artigos que fazem parte da coletânea descrita nesta resenha. Os textos contribuem para o debate sobre a necessidade de que todas as áreas tenham representação nos CEPs e na CONEP. Assim, a regulamentação da pesquisa pode ser definida como um "campo de tensões" que pressupõe que seja revista permanentemente, a partir dos avanços, transformações e necessidades de cada área, para não correr o risco da "burocratização da ética” (SARTI; DUARTE, 2013, p. 10).

\section{Referências}

BELTRÃO, J. F. Desafios à Antropologia: diálogos interculturais entre os “outros” de ontem, os protagonistas de hoje e os antropólogos "situados". In: SARTI, C.; DUARTE, L. F. D. (Orgs.). Antropologia e ética: desafios para a regulamentação. Brasília: ABA, 2013. p. 86105.

BRASIL. Conselho Nacional de Saúde. Resolução no 466, de 12 de dezembro de 2012. Aprova diretrizes e normas regulamentadoras de pesquisas envolvendo seres humanos. Brasília: CNS/MS, 2012.

CARDOSO, M. Etnografia entre "éticas": ética e pesquisa com populações indígenas. In: SARTI, C.; DUARTE, L. F. D. (Orgs.). Antropologia e ética: desafios para a regulamentação. Brasília: ABA, 2013. p. 131-171.

TELLO, M. Ética y antropología de la violencia. In: SARTI, C.; DUARTE, L. F. D. (Orgs.). Antropologia e ética: desafios para a regulamentação. Brasília: ABA, 2013. p. 172-229.

VÍCTORA, C. O ético e o legal nos processos de apropriação profissional da experiência social. In: SARTI, C.; DUARTE, L. F. D. (Orgs.). Antropologia e ética: desafios para a regulamentação. Brasília: ABA, 2013. p. 106-130. 